\title{
Arsenic trioxide and ascorbic acid interfere with the BCL2 family genes in patients with myelodysplastic syndromes: an ex-vivo study
}

Sara Galimberti ${ }^{1,6^{*}}$, Francesca Guerrini ${ }^{1}$, Flavia Salvi ${ }^{2}$, lacopo Petrini ${ }^{3}$, Daniela Gioia ${ }^{2}$, Emanuela Messa ${ }^{2}$, Giuseppe A Palumbo ${ }^{4}$, Daniela Cilloni ${ }^{5}$, Mario Petrini ${ }^{1}$ and Alessandro Levis ${ }^{2}$

\begin{abstract}
Background: Arsenic Trioxide (ATO) is effective in about 20\% of patients with myelodysplasia (MDS); its mechanisms of action have already been evaluated in vitro, but the in vivo activity is still not fully understood. Since ATO induces apoptosis in in vitro models, we compared the expression of 93 apoptotic genes in patients' bone marrow before and after ATO treatment. For this analysis, we selected 12 patients affected by MDS who received ATO in combination with Ascorbic Acid in the context of the Italian clinical trial NCT00803530, EudracT Number 2005-001321-28.

Methods: Real-time PCR quantitative assays for genes involved in apoptosis were performed using TaqMan ${ }^{\circledR}$ Assays in 384-Well Microfluidic Cards "TaqMan ${ }^{\circledR}$ Human Apoptosis Array".

Quantitative RT-PCR for expression of EVI1 and WT1 genes was also performed. Gene expression values (Ct) were normalized to the median expression of 3 housekeeping genes present in the card (18S, ACTB and GAPDH).

Results: ATO treatment induced up-regulation of some pro-apoptotic genes, such as HRK, BAK1, CASPASE-5, BAD, TNFRSF1A, and BCL2L14 and down-regulation of ICEBERG. In the majority of cases with stable disease, apoptotic gene expression profile did not change, whereas in cases with advanced MDS more frequently pro-apoptotic genes were up-regulated. Two patients achieved a major response: in the patient with refractory anemia the treatment down-regulated $69 \%$ of the pro-apoptotic genes, whereas $91 \%$ of the pro-apoptotic genes were up-regulated in the patient affected by refractory anemia with excess of blasts-1. Responsive patients showed a higher induction of BAD than those with stable disease. Finally, WT1 gene expression was down-regulated by the treatment in responsive cases.

Conclusions: These results represent the basis for a possible association of ATO with other biological compounds able to modify the apoptotic pathways, such as inhibitors of the BCL2 family.
\end{abstract}

Keywords: ATO, Ascorbic acid, Myelodysplastic syndromes, MDS, Apoptosis

\section{Introduction}

Arsenic Trioxide (ATO) is an ancient drug that, in the most recent years, has been rediscovered and evaluated for the treatment of promyelocytic leukemia, multiple myeloma, and myelodysplastic syndromes (MDS) [1].

In MDS, two phase-II multicenter trials have reported interesting results, either in low- or high-risk patients $[2,3]$, with hematological improvement rates of $20-30 \%$.

\footnotetext{
* Correspondence: sara.galimberti@med.unipi.it

${ }^{1}$ Department of Oncology, Transplant, New Advances in Medicine, Section of Hematology, University of Pisa, Pisa, Italy

${ }^{6}$ Division of Haematology, Department of Oncology, Transplant and Advances in Medicine, University of Pisa, Via Roma 67, Pisa 56126, Italy Full list of author information is available at the end of the article
}

More recently, arsenic trioxide has been used in combination with thalidomide and retinoic acid in high-risk MDS patients, resulting in response rate of $48 \%$ and efficacy of $25 \%$ [4].

ATO exerts its anticancer activity inducing apoptosis through the disequilibrium of apoptotic/anti-apoptotic BCL2 family members $[5,6]$ cytochrome $C$ release, loss of mitochondrial transmembrane potential, reactive oxygen species generation [1], inactivation of NF-kB $[7,8]$, and activation of caspases [9]. Moreover, an antiangiogenetic activity of ATO has also been reported [10]. Because stable MDS cell lines are still lacking, PML-RARa-negative acute myeloid leukemia HL60 cells 
are frequently adopted as in vitro models. Recently, our group reported synergistic effects for the combination of the proteasome inhibitor Bortezomib and ATO in HL60 cell line [11].

However, the in vivo mechanisms of action of ATO in MDS patients are still matter of debate. Since ATO induces apoptosis in vitro, we evaluated the expression of 93 apoptotic genes in patients' bone marrow before and after ATO plus Ascorbic Acid treatment, in the context of the Italian clinical trial NCT00803530, EudracT Number 2005-001321-28.

In addition, the expression of WT1 and EVI1 has been evaluated and correlated with those of the apoptotic genes, because of WT1 and EVI1 prognostic value in MDS [12,13].

\section{Patients and methods \\ Patients}

Twelve MDS patients receiving ATO plus Ascorbic Acid in the context of the clinical trial NCT00803530, EudracT Number 2005-001321-28 were selected for this molecular characterization. For these patients, RNA collected from the bone marrow immediately before the first administration of the treatment was available.

ATO was administered at a dosage of $0.3 \mathrm{mg} / \mathrm{Kg}$ during the first week of therapy, and at a dosage of $0.25 \mathrm{mg} / \mathrm{Kg}$ during the subsequent weeks (week 2 to 16 ); Ascorbic Acid was administered at $1000 \mathrm{mg}$ IV within 30 minutes after each arsenic trioxide infusion, for 16 consecutive weeks.

Table 1 summarizes patients' characteristics. Three $\mathrm{mL}$ of bone marrow blood were collected in an EDTA tube by needle aspiration just before the beginning of the treatment and after the last administration.

Patients were diagnosed in agreement with WHO criteria and classified according to the International Prognostic Scoring System (IPSS) and the WHO classification-based prognostic scoring system (WPSS), as previously described [14,15]. Treatment responses were assessed according to the International Working Group (IWG) criteria [16].

This study has been conducted in accordance with the Declaration of Helsinki, and all patients gave informed consent for the clinical trial and this molecular characterization.

\section{Gene expression assays}

RNA was extracted from bone marrow blood using RNeasy Mini Kit (QIAGEN, Valencia, CA, USA). Realtime PCR quantitative assays for genes involved in apoptosis were performed using TaqMan $^{\circledR}$ Assays in 384Well Microfluidic Cards "TaqMan ${ }^{\circledR}$ Human Apoptosis Array" (Catalog Number 4378701, Applied Biosystems, CA, USA). Real-time PCR was performed in a $7900 \mathrm{HT}$
Table 1 Patients' characteristics

\begin{tabular}{|c|c|c|}
\hline \multirow[t]{2}{*}{ Characteristics } & \multicolumn{2}{|c|}{ Patients } \\
\hline & No. & $\%$ \\
\hline Total patients enrolled & 12 & \\
\hline Median age, years & 69 & \\
\hline \multicolumn{3}{|l|}{ Sex } \\
\hline Male & 7 & 58 \\
\hline Female & 5 & 42 \\
\hline \multicolumn{3}{|l|}{ IPSS risk score } \\
\hline Low & 0 & 0 \\
\hline Intermediate 1 & 7 & 59 \\
\hline Intermediate 2 & 1 & 8 \\
\hline High & 4 & 33 \\
\hline \multicolumn{3}{|l|}{ WPSS risk score } \\
\hline Very low & 1 & 8 \\
\hline Low & 3 & 25 \\
\hline Intermediate & 0 & 0 \\
\hline High & 5 & 42 \\
\hline Very high & 3 & 25 \\
\hline \multicolumn{3}{|l|}{ WHO classification } \\
\hline RA & 3 & 25 \\
\hline RARS & 0 & 0 \\
\hline $\mathrm{RCMD}$ & 0 & 0 \\
\hline RCMD-RS & 0 & 0 \\
\hline RAEB1 & 5 & 42 \\
\hline RAEB2 & 4 & 33 \\
\hline \multicolumn{3}{|c|}{ Transfusion dependence at baseline } \\
\hline RBC only & 8 & 67 \\
\hline PLT only & 1 & 8 \\
\hline $\mathrm{RBC}+\mathrm{PLT}$ & 1 & 8 \\
\hline No & 2 & 17 \\
\hline
\end{tabular}

\begin{tabular}{lll}
\hline 0 & 0 & 0 \\
\hline 1 & 7 & 58 \\
\hline 2 & 5 & 42 \\
\hline 3 & 0 & 0
\end{tabular}

Hematological median values at enrollment

\begin{tabular}{lll}
\hline $\mathrm{N}\left(\times 10^{9} / \mathrm{L}\right)$ & 2,04 & \\
\hline $\mathrm{Hb}(\mathrm{g} / \mathrm{dL})$ & 8.9 & \\
\hline $\mathrm{PLT}\left(\times 10^{9} / \mathrm{L}\right)$ & 174 & \\
\hline Karyotype & & \\
\hline Normal & 5 & 42 \\
\hline Complex & 2 & 17 \\
\hline+8 & 1 & 8 \\
\hline Del7 & 1 & 8 \\
\hline Other abnormalities & 3 & 25
\end{tabular}

$\mathrm{RA}=$ refractory anemia, $\mathrm{RARS}=$ refractory anemia with ringed sideroblasts, $\mathrm{RCMD}=$ refractory cytopenia with multilineage dysplasia, RCMD-RS = refractory cytopenia with multilineage dysplasia and ringed sideroblasts, RAEB-

$1=$ refractory anemia with excess of blasts- 1, RAEB- 2 = refractory anemia with excess of blasts- 2 . 
Real-Time PCR System (Applied Biosystems) and data were analyzed using SDS 2.2 software.

Quantitative RT-PCR expression of EVI1 gene was performed as previously described [13]; quantitative WT1 expression was assessed by using the "WT1 ProfileQuant ${ }^{\circledR}$ kit" (Ipsogen, Marseille, France).

\section{Statistical analysis}

Gene expression was analyzed using GenespringGx 11.5 (Agilent, Palo Alto, CA, USA). Gene expression values $(\mathrm{Ct})$ were normalized to the median expression of three housekeeping genes present in the card (18S, ACTB and GAPDH). Normalized gene expression $(\Delta \mathrm{Ct})$ before and after treatment was compared using two tails paired $\mathrm{t}$ test. Differential gene expression before and after treatment was calculated $(-\Delta \Delta \mathrm{Ct})$ and differences between patients who experienced a response or not (stable disease vs major or minor responses) were evaluated by an unpaired t-test.

Ingenuity pathway analysis was adopted to explore the interaction between differently expressed genes.

To determine significances in categorized variables, SPSS 17.0 (SPSS Inc, Chicago, IL, USA) was used to calculate Pearson Chi-square or Fisher's exact test, when appropriate. All tests were 2-sided. Results were considered statistically significant for $\mathrm{p} \leq 0.05$.

\section{Results}

\section{Patients characteristics}

Characteristics of patients enrolled in this study are listed in the Table 1. Note that the purpose of this article was not the presentation of results arising from the clinical trial; of consequences, the characteristics listed in the Table are not fully representative of the whole series of patients.

Three patients were affected by refractory anemia (RA), 5 by refractory anemia with excess of blasts- 1 (RAEB1), and other 4 by refractory anemia with excess of blasts-2 (RAEB2). IPSS was intermediate- 1 in 7 cases, intermediate- 2 in one patient, and high in the remaining 4. Eight patients required red blood cell transfusion, one only platelet transfusion, and one both red blood cells and platelets support. The WPSS score was very low in one case, low in 3 , high in 5 , and very high in other 3 patients.

\section{Apoptotic genes expression}

First, we analyzed the gene expression profile of patient $\# 12$, considered as the "test patient"; indeed, expression levels of apoptotic and anti-apoptotic genes were analyzed the day before receiving arsenic trioxide and the day after the end of the loading phase (at day 6). This patient, affected by refractory anemia with excess of blasts-1, with IPSS intermediate-1 risk score, achieved a major response.

After treatment, 18 genes resulted up-regulated in this patient $(14 / 18=78 \%$, pro-apoptotic), and only 3 genes down-regulated (2 anti-apoptotic; Table 2).

Among the pro-apoptotic genes, those with higher increasing rate were HRK, BAK1, BCL2L14, and CASPASE-5.

In order to assess if the profile of the "test patient" could be reproduced in any remaining patients, an unsupervised clustered analysis was performed. Figure 1 depicts expression levels of assessed genes in the whole series.

As shown, the "test patient" (lane \#6), which was classified as RAEB1, with IPSS intermediate-1, and normal karyotype, tightly clustered together with patient \#4 (lane \#5), affected by RAEB2, and with patient \#7 (lane \#4), affected by RAEB1. These patients were scored as at high and intermediate-1 IPSS respectively; both showed normal karyotype and high WT1 levels.

When the gene expression profile was analyzed in the whole series, in 4 of the 6 cases with stable disease the gene expression profile did not significantly change (see patient \#2, \#7, \#10, and \#11 in Figure 1).

Table 2 Results from Quantitative RT-PCR assays in pt \#12 (the test patient)

\begin{tabular}{|c|c|c|c|}
\hline \multicolumn{2}{|c|}{ Gene identification } & \multirow{2}{*}{$\begin{array}{l}\text { Gene function } \\
\text { Pro-apoptosis }\end{array}$} & \multirow{2}{*}{$\begin{array}{l}2-\Delta \Delta C \mathrm{t} \\
36.1 \\
\end{array}$} \\
\hline BAK1 & Hs00832876_g1 & & \\
\hline BAX & Hs00751844_s1 & Pro-apoptosis & 5.5 \\
\hline $\mathrm{BCL} 2$ & Hs00608023_m1 & Anti-apoptosis & 3.2 \\
\hline BIM & Hs00708019_s1 & Pro-apoptosis & 4.4 \\
\hline BCL2L14 & Hs00373302_m1 & Pro-apoptosis & 21.6 \\
\hline $\mathrm{BIRC1}$ & Hs01847653_s1 & Anti-apoptosis & 10.7 \\
\hline $\mathrm{BIRC4}$ & Hs00745222_s1 & Anti-apoptosis & 8.1 \\
\hline BIRC8 & Hs01057786_s1 & Anti-apoptosis & 521.7 \\
\hline BNIP3 & Hs00969291_m1 & Pro-apoptosis & 15.7 \\
\hline BOK & Hs00261296_m1 & Pro-apoptosis & 5.4 \\
\hline CASPASE-5 & Hs00362072_m1 & Pro-apoptosis & 18.2 \\
\hline DEDD2 & Hs00370206_m1 & Pro-apoptosis & 2.8 \\
\hline HRK & Hs00705213_s1 & Pro-apoptosis & 338.8 \\
\hline LTA & Hs99999086_m1 & Pro-apoptosis & 13.1 \\
\hline LTB & Hs00242739_m1 & Pro-apoptosis & 7.1 \\
\hline TNFRSF1A & Hs01042313_m1 & Pro-apoptosis & 3.6 \\
\hline TRAIL & Hs00234356_m1 & Pro-apoptosis & 3.8 \\
\hline TRADD & Hs00601065_g1 & Pro-apoptosis & 3.4 \\
\hline BCL2L10 & Hs00368095_m1 & Pro-apoptosis & 0.32 \\
\hline $\mathrm{BIRC5}$ & Hs00977611_g1 & Anti-apoptosis & 0.41 \\
\hline BIRC7-LIVIN & Hs00223384_m1 & Anti-apoptosis & 0.38 \\
\hline
\end{tabular}

$2-\Delta \Delta \mathrm{Ct}$ lists how many times a gene is up- or de-regulated in bone marrow after ATO + ascorbic acid after treatment versus before therapy. 


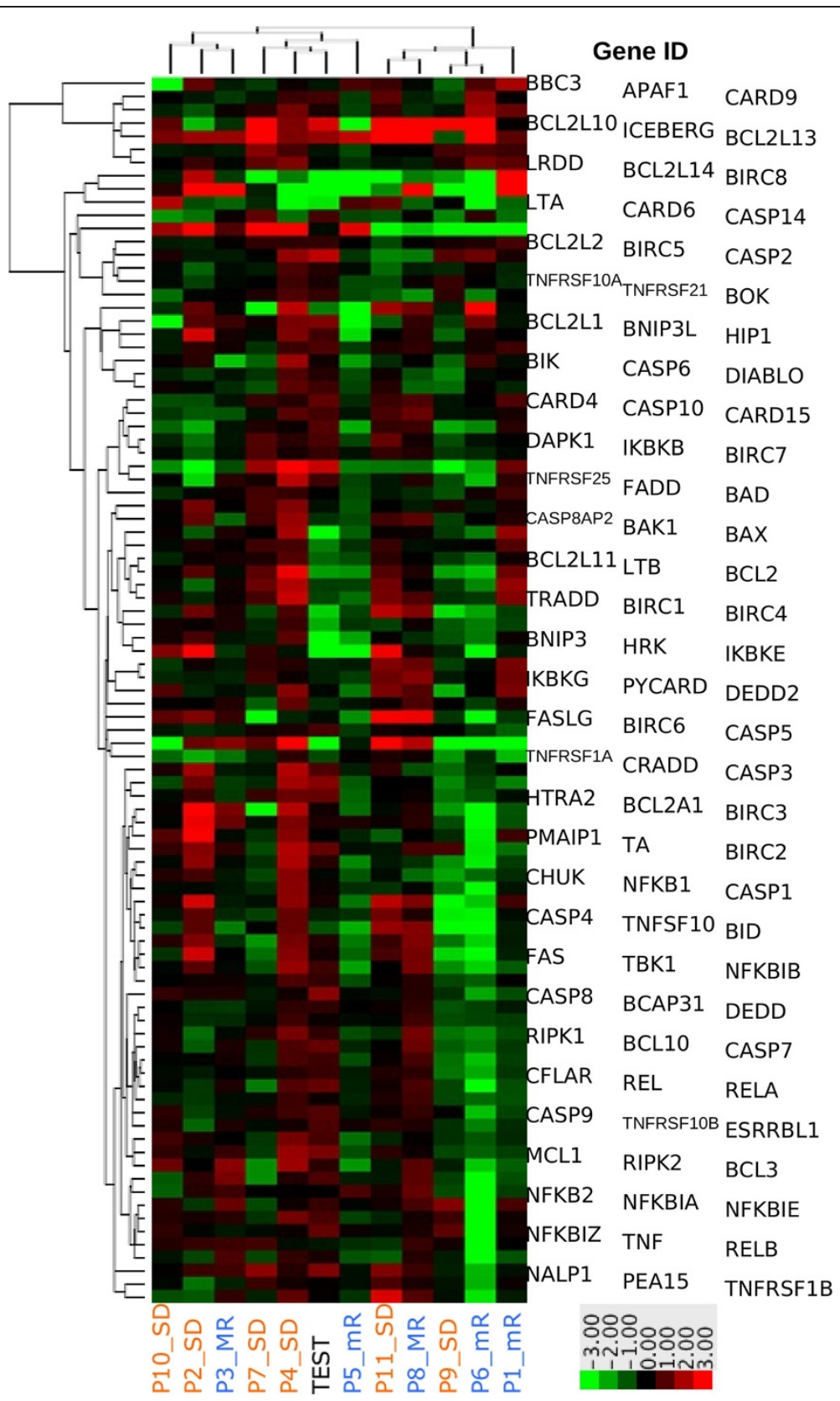

Figure 1 Unsupervised cluster analysis of apoptotic gene expression modification upon ATO and Ascorbic Acid treatment. Figure depicts $-\Delta \Delta$ Ct of the "test patient" (lane \#6) versus the remaining ones.

Three cases showed a minor response: among proapoptotic genes, resulted more frequently up-regulated: CASPASE-5, CASPASE-14, TNFRSF1A, HRK, BCL2L1, BCL2L14, TNFSF10, and LTB. On the contrary, BCL2L10 and BIRC8 were the anti-apoptotic genes whose expression was more frequently increased by ATO and Ascorbic Acid. In patient \#1, who showed an intermediate-1 IPSS, some genes belonging to the NF-kB pathways (NFKBIA, NFKBIE, NFKBIZ, RELB) were significantly up-regulated.
Two patients achieved a major response: in the patient with RA the treatment down-regulated $69 \%$ of the proapoptotic genes (see case \#3 in the Figure 1), whereas $91 \%$ of the pro-apoptotic genes were up-regulated in the patient affected by RAEB1 (case \#8).

When gene expression was further analyzed in respect of response, patients who reached a response (minor or major) showed a higher induction of BAD than those with stable disease (Figure 2). 

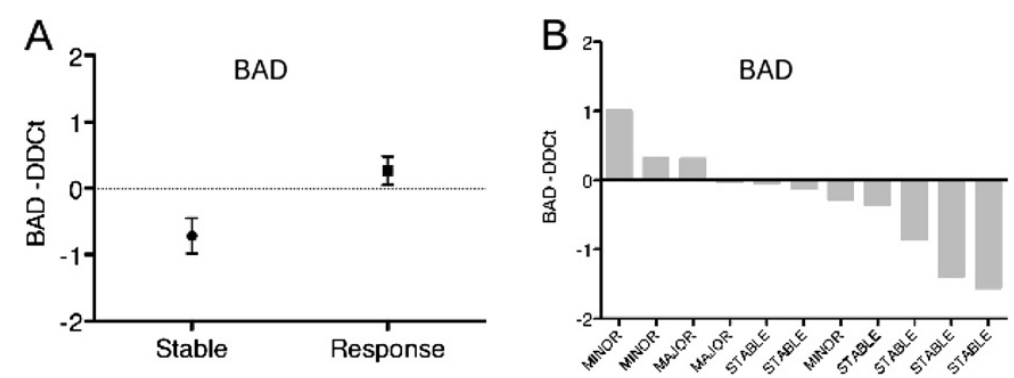

Figure 2 ATO and Ascorbic Acid induced gene expression modification of BAD in patients that reached stable disease or a response (major or minor).

Moreover, in the whole series, paired t-test demonstrated that ATO plus Ascorbic Acid induced downregulation of ICEBERG $(\mathrm{p}=0.0075)$, and up-regulation of TNFRSF1A $(\mathrm{p}=0.0172)$ and BCL2L14 $(\mathrm{p}=0.0384)$ in patients' bone marrow (Figure $3 \mathrm{~A}, \mathrm{~B}$ and $\mathrm{C}$, respectively).

Furthermore, we noticed a basal high expression of BCL2L10 in two patients affected by RAEB1 and AR, respectively. In these two patients, treatment induced a dramatic reduction of BCL2L10 expression. In the remaining cases, other 4 patients experienced a relevant reduction of BCL2L10 expression, but this reduction was not significant when the whole series was evaluated.

\section{Pathway analysis}

Ingenuity pathway analysis was adopted to explore the interaction between differently expressed genes. ICEBERG, TNFRS1A and BCL2L14 were included in the analysis because they were significantly de-regulated after treatment.
BAD was included because of its higher expression in responder cases. Also BAK1, HRK and BCL2L10 were included in this analysis because of their increased values in the "test" sample (Figure 4).

\section{Evaluation of expression of WT1 and EVI1 genes}

In the present study, we decided to assess if different values of WT1 and EVI1 measured at diagnosis and after treatment could be associated with the expression of several apoptotic genes, with particular interest in a possible common de-regulation.

At diagnosis, 10 patients showed high levels of WT1; after therapy, in 4 of them a significant reduction of the transcript was observed. Interestingly, 3 of them were the cases that achieved the major response; the correlation between reduction of the WT1 levels and good response was significant $(\mathrm{p}=0.024)$.

EVI1 gene expression was detectable at diagnosis in 10 patients, 3 cases with high levels.
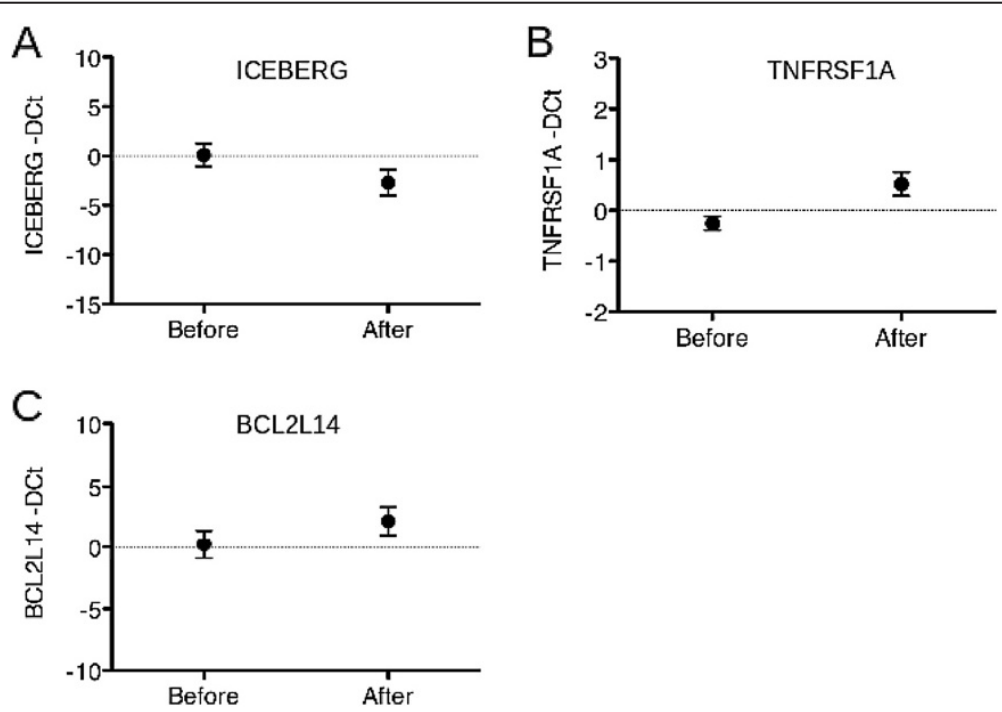

Figure 3 Mean and standard deviation of gene expression before and after ATO and Ascorbic Acid treatment of ICEBERG (A), TNFRSF1A (B) and BCL2L14 (C) in the whole series of patients. 


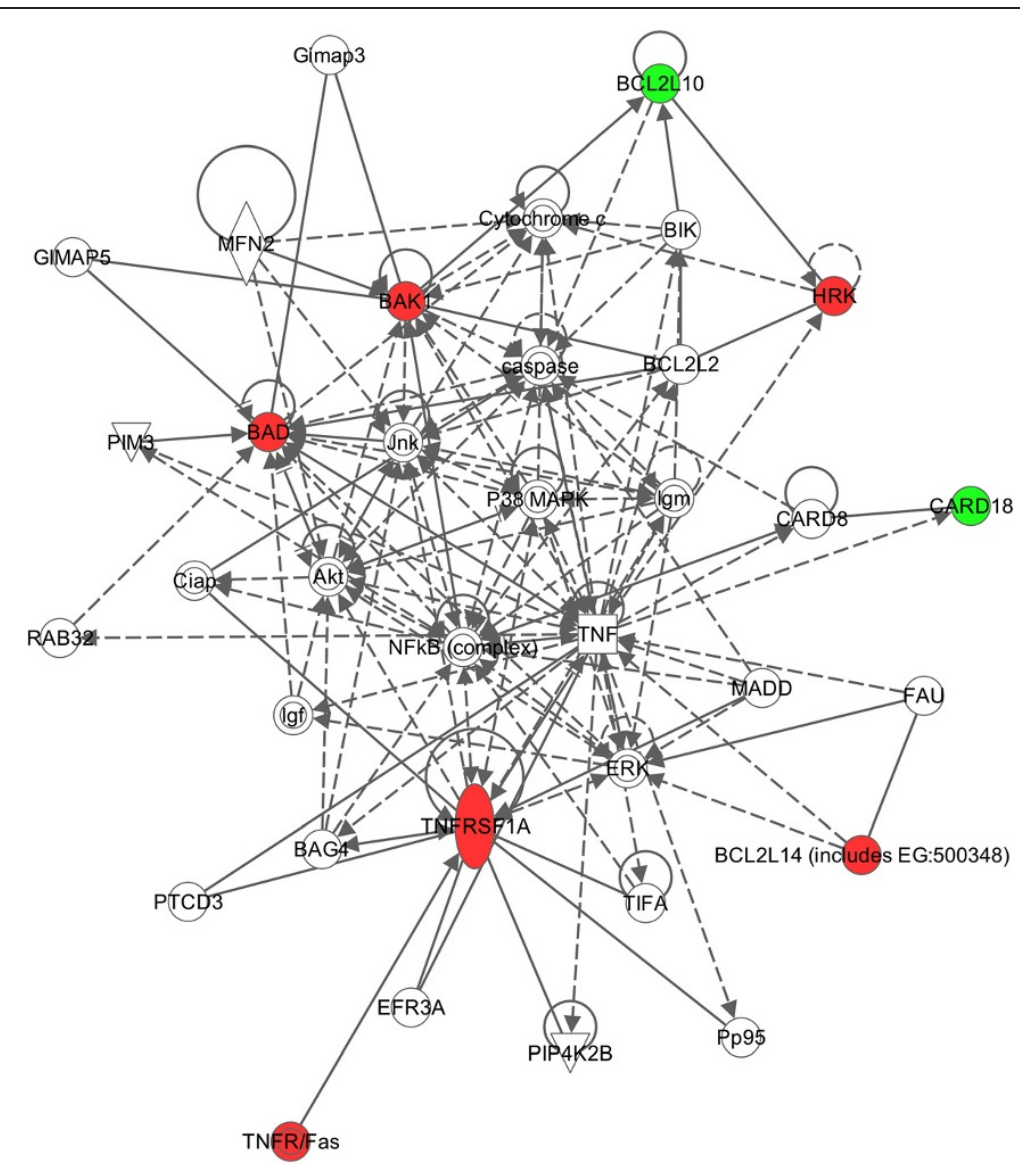

Figure 4 Relationships between differentially expressed genes have been explored in the pathway analysis. Up-regulated genes are reported in red, whereas down-regulated in green.

After therapy, 3 of them showed a significant reduction of the transcript. In the group of patients with low levels before treatment, only one showed increased levels (Table 3). No significant correlation between the

Table 3 WT1 and EVI1 expression levels before and after treatment and their correlation with clinical response are reported

\begin{tabular}{llllll}
\hline Pt ID & WT1 @ start & WT1 @ end & EVI1 @ start & EVI1 @ end & response \\
\hline $\mathbf{1}$ & high & high & low & low & minor \\
$\mathbf{2}$ & high & high & low & low & stable \\
$\mathbf{3}$ & high & normal & low & low & major \\
$\mathbf{4}$ & high & normal & low & low & stable \\
$\mathbf{5}$ & normal & normal & high & low & minor \\
$\mathbf{6}$ & normal & normal & low & low & minor \\
$\mathbf{7}$ & high & high & high & low & stable \\
$\mathbf{8}$ & high & normal & low & high & major \\
$\mathbf{9}$ & high & high & low & low & stable \\
$\mathbf{1 0}$ & high & high & N/A & N/A & stable \\
$\mathbf{1 1}$ & high & high & high & low & stable \\
$\mathbf{1 2}$ & high & normal & N/A & N/A & major \\
\hline
\end{tabular}

behavior of the EVI1 expression and the quality of response, disease progression or death was found.

Moreover, no correlation between expression of WT1 and EVI1 (either measured at diagnosis or after therapy) and de-regulation of the pro- and anti-apoptotic assessed genes was observed.

\section{Discussion}

It is well known that myelodysplastic syndromes are very heterogeneous entities, characterized by accelerated rates of apoptosis in early stages and higher proliferation, accumulation of less differentiated cells, with high genomic instability in the advanced phases.

Consequently, it is really difficult to derive any conclusive results from the gene expression profiling of few MDS patients. Moreover, molecular studies performed in patients receiving ATO that could increase the knowledge about real mechanisms of its action are still lacking, thus a homogenously treated series of patients, even if small, could represent a good opportunity in this field.

Here, we evaluated 12 patients affected by advanced and resistant MDS receiving ATO and Ascorbic Acid for 
16 weeks. The aim was to assess ex vivo what was previously observed in vitro by our group also, with particular interest in the apoptotic pathways.

Thus, we evaluated by quantitative real-time PCR the expression of 93 genes involved in apoptosis in a "test patient" (who was analyzed just before and soon after treatment), and in other 3 patients affected by RA, 4 by RAEB1, and 4 by RAEB2.

As reported in the result section, in 4 of 6 cases with stable disease the gene expression profile did not significantly change. Two patients achieved a major response: in the patient with RA the treatment with ATO and Ascorbic Acid down-regulated about $60 \%$ of the proapoptotic genes, whereas, in the patient affected by RAEB, $91 \%$ of the pro-apoptotic genes were up-regulated. This observation could have a clinical impact, if we consider that in the early phases of MDS the goal of treatment would be the reduction of apoptosis and inflammatory status, whereas in the more advanced phases a perfect drug would exert principally an antiproliferative effect.

Another interesting result from the present study is the demonstration that among principal targets for ATO there are genes belonging to the BCL2 family, analogously to that already observed in vitro. Interestingly, responsive patients showed a higher induction of BAD than those with stable disease. High expression of the pro-apoptotic BCL2-family proteins (BAK, BAD, BCL$\mathrm{XS}$, as well the apoptosis facilitator BCL2L14) has been previously associated with longer survival and decreased risk of leukemic transformation [17]. In our series, BCL2L14 expression was significantly increased by ATO and Ascorbic Acid, both in the "test patient" and in responsive cases. On the other hand, the expression of BCL2L10, an anti-apoptotic gene, resulted significantly down-regulated in 4 cases, as observed in the "test patient".

Moreover, the expression of ICEBERG was significantly reduced in 8 cases; this gene physiologically inhibits caspase- 1 activity. Caspase- 1 is able to activate the IL- $1 \beta$ precursor; this could be interesting, because various myelosuppressive and pro-inflammatory cytokines have been implicated in the high rates of apoptosis and hematopoietic suppression seen in MDS $[17,18]$. Thus, decreased expression of ICEBERG could be a relevant target for new therapeutic strategies in early MDS.

Another gene that was significantly up-regulated after treatment is the TNFRSFA1 (Tumor necrosis factor receptor super family member $1 \mathrm{~A}$ ); its protein is one of the major receptors for the TNF $\alpha$, and it is physiologically able to mediate apoptosis [19]. Consequently, its upregulation could be another interesting target for treatments in advanced MDS.
Finally, a significant association between low WT1 levels and good response was found, in line with the negative prognostic role of WT1 in MDS progression previously shown [20].

Recently, immunological approaches to inactivate WT1 in acute leukemia and high-risk MDS have been proposed: these studies provided preliminary evidences of potential clinical efficacy in these patients [21].

\section{Conclusions}

In conclusion, the present study to our knowledge is the first one that analyzed gene expression profile in a homogeneously treated series of MDS patients receiving ATO plus Ascorbic Acid. It confirmed ex vivo some mechanisms of action already demonstrated in vitro. In particular, genes belonging to the BCL2 family appeared particularly relevant in the conditioning outcome of MDS patients; this observation could translate in a possible promising therapeutic approach with BCL2 inhibitors [22].

\section{Ethics approval}

This trial was registered as EudracT Number 2005001321-28.

This study was conducted in accordance with the Declaration of Helsinki, and all patients gave informed consent for molecular tests.

\section{Abbreviations \\ (ATO): Arsenic Trioxide; (MDS): Myelodysplastic syndromes; (IPSS): International Prognostic Scoring System; (WPSS): WHO classification-based prognostic scoring system; (IWG): International Working Group; RA: refractory anemia; RARS: Refractory anemia with ringed sideroblasts; RCMD: Refractory cytopenia with multilineage dysplasia; RCMD-RS: Refractory cytopenia with multilineage dysplasia and ringed sideroblasts; RAEB-1: Refractory anemia with excess of blasts-1; RAEB-2: Refractory anemia with excess of blasts-2.}

\section{Competing interests}

The authors have not competing interests to declare.

\section{Authors' contributions}

GS designed the study, analyzed data, and wrote the manuscript; Guerrini F, Cilloni D, and Palumbo GA performed PCR assays; SF, GD, ME, LA, were principal investigators in the clinical trial; PI and PM analyzed data, and revised the manuscript. All authors read and approved the final manuscript

\section{Acknowledgements}

University of Pisa founded this research. We acknowledge Morrow Betsy for her support in reviewing the article grammar. Warm thanks to all centers participating to the clinical trial.

\section{Author details}

${ }^{1}$ Department of Oncology, Transplant, New Advances in Medicine, Section of Hematology, University of Pisa, Pisa, Italy. ${ }^{2}$ S.O.C. di Ematologia, Azienda

Ospedaliera SS Antonio e Biagio, Alessandria, Italy. ${ }^{3}$ Department of Oncology, Transplant and New Advances in Medicine, BIOS, University of Pisa, Pisa, Italy. ${ }^{4}$ Department of Clinical and Molecular Bio-Medicine, Section of Hematology, Oncology and General Pathology, Catania, Italy. ${ }^{5}$ Department of Clinical and Biological Sciences, University of Turin, Turin, Italy. 'Division of Haematology, Department of Oncology, Transplant and Advances in Medicine, University of Pisa, Via Roma 67, Pisa 56126, Italy. 
Received: 9 July 2012 Accepted: 27 August 2012

Published: 10 September 2012

\section{References}

1. Ho SY, Wu WJ, Chiu HW, Chen YA, Ho YS, Guo HR, Wang YJ: Arsenic trioxide and radiation enhance apoptotic effects in HL-60 cells through increased ROS generation and regulation of JNK and p38 MAPK signaling pathways. Chem Biol Interact 2011, 193:162-167.

2. Schiller GJ, Slack J, Hainsworth JD, Mason J, Saleh M, Rizzieri D, Douer D, List AF: Phase II multicenter study of arsenic trioxide in patients with myelodysplastic syndromes. J Clin Oncol 2006, 24:2456-2464.

3. Vey N, Bosly A, Guerci A, Feremans W, Dombret H, Dreyfus F, Bowen D, Burnett A, Dennis M, Ribrag V, Casadevall N, Legros L, Fenaux P: Arsenic trioxide in patients with myelodysplastic syndromes: a phase II multicenter study. J Clin Oncol 2006, 24:2465-2471.

4. Zheng WL, Zhang GS, Xu YX, Shen JK, Dai CW, Pei MF: Arsenic trioxide, thalidomide and retinoid acid combination therapy in higher risk myelodysplastic syndrome patients. Leuk Res 2008, 32:251-254.

5. Perkins C, Kim CN, Fang G, Bhalla KN: Arsenic induces apoptosis of multidrug-resistant human myeloid leukemia cells that express Bcr-Abl or overexpress MDR, MRP, Bcl-2, or Bcl-x(L). Blood 2000, 95:1014-1022.

6. Scholz C, Richter A, Lehmann M, Schulze-Osthoff K, Dorken B, Daniel PT: Arsenic trioxide induces regulated, death receptor-independent cell death through a Bcl-2-controlled pathway. Oncogene 2005, 24:7031-7042.

7. Mathas S, Lietz A, Janz M, Hinz M, Jundt F, Scheidereit C, Bommert K, Dorken B: Inhibition of NF-kappa B essentially contributes to arsenicinduced apoptosis. Blood 2003, 102:1028-1034.

8. Yedjou C, Tchounwou P, Jenkins J, McMurray R: Basic mechanisms of arsenic trioxide (ATO)-induced apoptosis in human leukemia (HL-60) cells. J Hematol Oncol 2010, 23:28.

9. Huang XJ, Wiernik PH, Klein RS, Gallagher RE: Arsenic trioxide induces apoptosis of myeloid leukemia cells by activation of caspases. Med Oncol 1999, 16:58-64.

10. Roboz GJ, Dias S, Lam G, Lane WJ, Soignet SL, Warrell RP Jr, Rafii S: Arsenic trioxide induces dose- and time-dependent apoptosis of endothelium and may exert an antileukemic effect via inhibition of angiogenesis. Blood 2000, 96:1525-1530.

11. Canestraro M, Galimberti S, Savli H, Palumbo GA, Tibullo D, Nagy B, Guerrini F, Piaggi S, Cine N, Metelli MR, Petrini M: Synergistic antiproliferative effect of arsenic trioxide combined with bortezomib in HL60 cell line and primary blasts from patients affected by myeloproliferative disorders. Cancer Genet Cytogenet 2010, 199:110-120.

12. Galimberti S, Ghio F, Guerrini F, Ciabatti E, Grassi S, Ferreri MI, Petrini M: WT1 expression levels at diagnosis could predict long-term time-toprogression in adult patients affected by acute myeloid leukaemia and myelodysplastic syndromes. Br J Haematol 2010, 149:451-454.

13. Shackelford D, Kenific C, Blusztajn A, Waxman S, Ren R: Targeted degradation of the AML1/MDS1/EVI1 oncoprotein by arsenic trioxide. Cancer Res 2006, 66:11360-11369.

14. Malcovati L, Germing U, Kuendgen A, Della Porta MG, Pascutto C, Invernizzi R, Giagounidis A, Hildebrandt B, Bernasconi P, Knipp S, Strupp C, Lazzarino M, Aul C, Cazzola M: Time-dependent prognostic scoring system for predicting survival and leukemic evolution in myelodysplastic syndromes. J Clin Oncol 2007, 25:3503-3510.

15. Sanz GF, Sanz MA, Greenberg PL: Prognostic factors and scoring systems in myelodysplastic syndromes. Haematologica 1998, 83:358-368.

16. Cheson BD, Greenberg PL, Bennett JM, Lowenberg B, Wijermans PW, Nimer SD, Pinto A, Beran M, de Witte TM, Stone RM, Mittelman M, Sanz GF, Gore SD, Schiffer CA, Kantarjian H: Clinical application and proposal for modification of the International Working Group (IWG) response criteria in myelodysplasia. Blood 2006, 108:419-425.

17. Boudard D, Sordet O, Vasselon C, Revol V, Berthéas MF, Freyssenet D, Viallet A, Piselli S, Guyotat D, Campos L: Expression and activity of caspases 1 and 3 in myelodysplastic syndromes. Leukemia 2000, 14:2045-2051.

18. Navas $T$, Zhou L, Estes M, Haghnazari E, Nguyen AN, Mo Y, Pahanish P, Mohindru M, Cao T, Higgins LS, Platanias LC, List A, Verma A, Bhagat T, Gajavelli S, Kambhampati S: Inhibition of p38alpha MAPK disrupts the pathological loop of proinflammatory factor production in the myelodysplastic syndrome bone marrow microenvironment. Leuk Lymphoma 2008, 49:1963-1975.
19. Schall TJ, Lewis M, Koller KJ, Lee A, Rice GC, Wong GH, Gatanaga T, Granger GA, Lentz R, Raab H: Molecular cloning and expression of a receptor for human tumor necrosis factor. Cell 1990, 61:361-370.

20. Nolte F, Hofmann WK: Molecular mechanisms involved in the progression of myelodysplastic syndrome. Future Oncol 2010, 6:445-455.

21. Keilholz U, Letsch A, Busse A, Asemissen AM, Bauer S, Blau IW, Hofmann WK Uharek L, Thiel E, Scheibenbogen C: A clinical and immunologic phase 2 trial of Wilms tumor gene product 1 (WT1) peptide vaccination in patients with AML and MDS. Blood 2009, 113:6541-6548.

22. Tse C, Shoemaker AR, Adickes J, Anderson MG, Chen J, Jin S, Johnson EF, Marsh KC, Mitten MJ, Nimmer P, Roberts L, Tahir SK, Xiao Y, Yang X, Zhang H, Fesik S, Rosenberg SH, Elmore SW: ABT-263: a potent and orally bioavailable Bcl-2 family inhibitor. Cancer Res 2008, 68:3421-3428.

doi:10.1186/1756-8722-5-53

Cite this article as: Galimberti et al: Arsenic trioxide and ascorbic acid interfere with the BCL2 family genes in patients with myelodysplastic syndromes: an ex-vivo study. Journal of Hematology \& Oncology 2012 5:53.

\section{Submit your next manuscript to BioMed Central and take full advantage of:}

- Convenient online submission

- Thorough peer review

- No space constraints or color figure charges

- Immediate publication on acceptance

- Inclusion in PubMed, CAS, Scopus and Google Scholar

- Research which is freely available for redistribution

Submit your manuscript at www.biomedcentral.com/submit
C) Biomed Central 